Journal of Systems Science and Information

Feb., 2017, Vol. 5, No. 1, pp. 88-96

DOI: $10.21078 /$ JSSI-2017-088-09

\title{
Using Grey Relational Analysis with Entropy to Predict the International Financial Center of China
}

\author{
Hang JIANG \\ Ph.D. Program in Business, Chung Yuan Christian University, Chung Li Dist., Taoyuan City, \\ Taiwan, China; School of Business and Administration, Jimei University, Xiamen, China \\ Jan-Yan LIN \\ Department of Business Administration, Chung Yuan Christian University, Taoyuan City, Taiwan, \\ China \\ Peng JIANG \\ Department of Business Administration, Chung Yuan Christian University, Taoyuan City, Taiwan, \\ China \\ E-mail: jiangpeng1006@hotmail.com
}

\begin{abstract}
The establishment of the China Pilot Free Trade Zone (FTZ) has significantly promoted international trade, financial development, and economic growth. Building international financial centers (IFCs) satisfies the demand for FTZs to facilitate financial development, as well as promoting economic growth. Thus, successfully predicting the next IFC in China under the FTZ framework is an important issue. In this study, we applied grey relational analysis combined with entropy method to predict potential IFCs among seven FTZ cities. According to the results, our interesting findings include: 1) the "total stock turnover", "total value of imports and exports", and "Foreign Direct Investment (FDI)" are key indicators for determining future IFCs; 2) among seven cities, Shenzhen and Tianjin are highly likely to become the next IFCs, while Shanghai is already an IFC.
\end{abstract}

Keywords international financial center; multiple-criteria decision making; grey relational analysis; entropy

\section{Introduction}

Since 2013, China has established four national Pilot Free Trade Zones (FTZs) in Shanghai city, Guangdong Province, Tianjin city, and Fujian Province, including seven cities, as shown in Table 1. The establishment of FTZs is a signal that China hopes to open up further and promote financial reformation ${ }^{[1]}$, thereby avoiding large bank monopolies, opening market access to foreign financial institutions, and reducing the risk of international financial markets ${ }^{[2]}$. Moreover, the establishment of FTZs will make a great contribution to building international financial centers (IFCs) ${ }^{[3]}$, because FTZs promote international trade and facilitate investment. According to Bao ${ }^{[1]}$, by easing and abolishing restrictions on market access, FTZs can attract foreign investment and multinational trading, as well as enhancing the effects of capital flows.

Received April 23, 2016, accepted July 6, 2016 
In addition, according to their advantages in terms of their locations, FTZs have the capacity to accelerate the agglomeration of financial resources ${ }^{[4]}$. Therefore, FTZs can be the catalysts for the establishment of IFCs $^{[1]}$. A financial center will act as a regional financial growth pole, thereby generating a polarization and diffusion effect on capital ${ }^{[5]}$, as well as reducing the financing costs inside FTZs and greatly promoting economic growth in the local and surrounding areas ${ }^{[6]}$. In order to accelerate the development of IFCs, it has been proposed that all FTZs would ease investment restrictions and promote financial innovation. Therefore, deciding the locations of future IFCs under the FTZ framework is a very important issue.

Table 1 Introduction of FTZs in China

\begin{tabular}{ll}
\multicolumn{2}{c}{ Table 1 Introduction of FTZs in China } \\
\hline FTZ & Cities \\
\hline China (Shanghai) Pilot Free Trade Zone & Shanghai (SHA) \\
& Guangzhou (CAN) \\
China (Guangdong) Pilot Free Trade Zone & Shenzhen (SZX) \\
& Zhuhai (ZUH) \\
China (Tianjin) Pilot Free Trade Zone & Tianjin (TSN) \\
China (Fujian) Pilot Free Trade Zone & Fuzhou (FOC) \\
& Xiamen (XMN) \\
\hline
\end{tabular}

In the past, various methods have been employed in useful studies of IFC performance. Liu and Strange ${ }^{[7]}$ applied hierarchical clustering analysis and principal components analysis to rank the main financial centers in the Asia-Pacific region, and to identify the key factors that might affect their establishment. $\mathrm{Lu}^{[8]}$ used experts and multivariate statistical analysis to establish an IFC competitiveness index. Liu ${ }^{[9]}$ established an IFC evaluation index to test the significance of evaluation indicators based on regression and parametric testing methods. $\mathrm{Su}^{[10]}$ employed the Delphi method to establish a framework for IFC after two rounds of expert consultations. Liang, et al. ${ }^{[11]}$ applied entropy, grey relational analysis (GRA), principal components analysis, and cluster analysis separately to evaluate the multilayer system of financial centers in China and they compared the rankings with different methods.

These previous studies have proposed many useful directions for further research, but most of them neglected the differences in importance of indicators and they gave all indicators equal weight. Thus, like the multiple-criteria decision making (MCDM) problem, it is necessary to define the weights of factors. In this study, we introduce an approach based on entropy to identify the relative weights of indicators. We then use the entropy weights to calculate the grey relational grade (GRG) to rank seven FTZ cities as possible IFCs. Therefore, GRA combined with entropy can be employed to predict the next IFCs in China.

\section{Methodology}

Deng ${ }^{[12]}$ introduced grey system theory, and it is frequently employed to deal with uncertain and insufficient information. The main principle of this theory is recognizing the hidden data contained in indirect data by accumulating a generation operator ${ }^{[13]}$. The GRA procedure is employed to test the extent of connections between two digits by applying the departing 
and scattering measurement method to actual distance measurements ${ }^{[14]}$. Clearly, GRA is an effective method for dealing with the MCDM problem ${ }^{[15,16]}$.

Clausius introduced the theory of entropy in 1865 and it is generally used for calculating weights $^{[17]}$. It has been employed widely for evaluating the degree of disorder and the effectiveness of information in a system ${ }^{[18]}$. In addition, entropy can be applied to deal with location problems, where it measures the expected asymptotically optimal planar point location ${ }^{[19]}$. In particular, the entropy method is useful for calculating weights from secondary data ${ }^{[20]}$. Thus, GRA combined with entropy may be suitable for predicting the next IFCs in China. The calculation procedure is presented as follows.

Step 1 Grey relational generating

Different attributes are measured using different units, so the impacts of some attributes may be neglected ${ }^{[17]}$. Before calculating the relations, the original data should be normalized using Equation (1) to avoid data distortion.

Upper bound effectiveness of measurement (i.e., larger is better)

$$
p_{i j}=x_{i j} / x_{j}^{\max },
$$

where $x_{j}^{\max }$ is the maximum value of the $j$ th attribute.

Step 2 Reference sequence definition

We find the reference sequence in the normalized matrix. We then define the reference sequence.

$$
p^{*}=\left(p_{1}^{*}, p_{2}^{*}, \cdots, p_{j}^{*}\right)=(1,1, \cdots, 1) .
$$

Step 3 Grey relational coefficient (GRC) calculation

$$
\gamma_{i j}=\frac{\Delta_{\min }+\zeta \Delta_{\max }}{\Delta_{i j}+\zeta \Delta_{\max }}
$$

where $\Delta_{i j}=\left|p_{i j}^{*}-p_{i j}\right|, \Delta_{\min }=\min \Delta_{i j}, \Delta_{\max }=\max \Delta_{i j}$ and $\zeta$ is the distinguishing coef-

ficient, $\zeta \in[0,1]$. In most situations, $\zeta=0.5$, because this value usually allows moderate distinction and good stability ${ }^{[21]}$.

Step 4 Entropy weight calculation

Typically, an equal weight is assigned to various indicators when calculating the GRG ${ }^{[22-25]}$. However, it is important to note that equal weights might not reflect the importance of each indicator. In order to address this issue, we employ the entropy method to obtain the weights of indicators.

Define the attribute $j, p_{i j}$

$$
p_{i j}=x_{i j} / \sum_{i=1}^{m} x_{i j}
$$

The entropy $e_{j}$ of the set of attributes $j$ is

$$
e_{j}=-k \sum_{j=1}^{n} p_{i j} \ln p_{i j}, \quad \forall j
$$

where $k$ is Boltzmann's constant, which equals $k=1 / \ln m$ and this guarantees that $0 \leq e_{j} \leq 1$. 
The degree of diversification $d_{j}$ of attribute $j$ can defined as

$$
d_{j}=1-e_{j}
$$

We make the relative weights within the range $(0,1)$ satisfy the equal weight limitation of GRA:

$$
w_{i j}=d_{j} / \sum_{j=1}^{n} d_{j}
$$

where $\sum_{j=1}^{n} w_{j}=1$.

Step 5 GRG calculation

$$
\Gamma=\sum_{j=1}^{n} w_{j} \gamma_{i j}
$$

where $w_{j}$ is obtained using Equation (6).

The GRG denotes the degree of similarity between the comparative sequence and the reference sequence $^{[26]}$. Hence, when the GRG of the comparative sequence is higher, it is more similar to the reference sequence, and this alternative would be the best choice ${ }^{[24]}$.

\section{Empirical Study}

In this study, we used GRA with entropy to predict the next IFCs in China. First, according to the steps described above, we calculated the relative weights of IFC criteria based on their entropy. Next, we ranked seven cities in terms of their performance by GRA.

\subsection{Determination of the Indicators and Data Collection}

In this study, the cities that might potentially be selected as IFCs are shown in Table 1. IFC assessment is a complex process, where many factors can affect the decision ${ }^{[27]}$. Many previous studies have developed indices to evaluate the performance of IFC ${ }^{[11]}$. Thus, Huang ${ }^{[27]}$ used the Gross Domestic Product (GDP) growth rate, investment rate, financial sector output contribution, and stocks traded/GDP to compare the financial performance of IFCs and non-IFCs. $\mathrm{Hu}$ and Yang ${ }^{[28]}$ used three groups of seven indicators, i.e., economy, finance, and politics, with the GDP growth rate, investment ratio, financial sector output/GDP, stock investment/GDP, degree of maturity of the financial market, financial market transparency, political risk rating. Liu ${ }^{[9]}$ employed seven indicators with economic, financial, talent, and political dimensions. $\mathrm{Hu}$ and $\mathrm{Xia}^{[29]}$ established an index that comprised 42 indicators in four groups. Liang, et al. ${ }^{[11]}$ evaluated the urban financial competitiveness based on 45 indicators in five dimensions. Huang ${ }^{[30]}$ estimated a regional financial center by using 19 indicators in four dimensions. According to these previous studies, we developed an evaluation index, as shown in Table 2.

The seven IFC cities examined in this study all satisfied the 10 evaluation indicators and all of the indicators had larger-is-better attributes. Based on data accessibility and objectivity, data for the 10 indicators were collected from the Statistic Yearbook (2010-2014), National Economic and Social Development Statistics Bulletin (2010-2014), and Financial Performance Report (2010-2014).

Table 2 shows all of the indicators terms of their financial performance, economic foundation, and development potential. 
Table 2 Evaluation index of IFC

\begin{tabular}{lll}
\hline Aspect & Indicator & Reference \\
\hline & $I_{1}$ No. of financial sector employee & {$[9,11,28-30]$} \\
& $I_{2}$ Financial institutions deposit and loan balance & {$[11,28,30]$} \\
Financial performance & $I_{3}$ Total stock turnover & {$[9,11,27]$} \\
& $I_{4}$ Total premium income & {$[11,30]$} \\
& $I_{5}$ Gross domestic product (GDP) & {$[9,11,27,30]$} \\
Economic foundation & $I_{6}$ Total retail sales of consumer goods & {$[11,27,30]$} \\
& $I_{7}$ Freight traffic & {$[11,27,30]$} \\
& $I_{8}$ Total value of imports and exports & {$[28,30]$} \\
Development potential & $I_{9}$ Foreign direct investment (FDI) & {$[28,30]$} \\
& $I_{10}$ No. of enrolments of colleges and universities & {$[29,30]$} \\
\hline
\end{tabular}

The raw data for the 10 indicators of the seven cities are shown in Table 3 .

Table 3 Raw data of IFC's indicators

\begin{tabular}{lcccccccccc}
\hline & $I_{1}$ & $I_{2}$ & $I_{3}$ & $I_{4}$ & $I_{5}$ & $I_{6}$ & $I_{7}$ & $I_{8}$ & $I_{9}$ & $I_{10}$ \\
\hline SHA & 290860.00 & 104335.53 & 262720.00 & 853.16 & 20384.50 & 7413.65 & 90118.58 & 7947.72 & 147.71 & 50.90 \\
CAN & 112961.60 & 50022.08 & 37234.54 & 463.04 & 13769.80 & 6055.47 & 76837.14 & 1173.13 & 45.47 & 93.63 \\
SZX & 135928.80 & 51690.61 & 272130.86 & 428.02 & 12907.86 & 3961.60 & 28895.92 & 4505.52 & 50.80 & 7.66 \\
ZUH & 18730.00 & 5479.97 & 4245.43 & 57.86 & 1527.40 & 645.06 & 8250.51 & 499.91 & 15.25 & 12.38 \\
TSN & 138140.00 & 38930.22 & 11992.06 & 251.69 & 12718.02 & 3885.62 & 47302.07 & 1127.31 & 149.23 & 46.25 \\
FOC & 138140.00 & 38930.22 & 11992.06 & 251.69 & 12718.02 & 3885.62 & 47302.07 & 1127.31 & 149.23 & 46.25 \\
XMN & 20574.00 & 10774.52 & 15260.00 & 99.10 & 2741.25 & 882.93 & 14963.26 & 738.69 & 17.69 & 15.77 \\
\hline
\end{tabular}

\subsection{GRC Calculation}

All of the indicators had larger-is-better attributes, so Equation (1) was used to normalize the initial matrix and the results obtained after normalization are shown in Table 4.

The reference sequence was set as $p^{*}=(1,1, \cdots, 1)$ and we aimed to find the alternative where the comparability sequence was the closest to the reference sequence. Thus, Equation (2) was used to calculate the GRC and the results are presented in Table 5.

\subsection{Entropy Weight Calculation}

The weights of the indicators were determined by entropy. Table 6 shows the entropy weights for the 10 indicators of the seven cities obtained using Equation (3) to Equation (6). The entropy weights range from 0.0637 to 0.2031 . The top three indicators are "total stock turnover", "total value of imports and exports", and "Foreign Direct Investment (FDI)", while "freight traffic", "GDP", and "total retail sales of consumer goods" are the last three. 
Table 4 Normalized matrix

\begin{tabular}{lcccccccccc}
\hline & $I_{1}$ & $I_{2}$ & $I_{3}$ & $I_{4}$ & $I_{5}$ & $I_{6}$ & $I_{7}$ & $I_{8}$ & $I_{9}$ & $I_{10}$ \\
\hline SHA & 1.0000 & 1.0000 & 0.9654 & 1.0000 & 1.0000 & 1.0000 & 1.0000 & 1.0000 & 0.9898 & 0.5436 \\
CAN & 0.3884 & 0.4794 & 0.1368 & 0.5427 & 0.6755 & 0.8168 & 0.8526 & 0.1476 & 0.3047 & 1.0000 \\
SZX & 0.4673 & 0.4954 & 1.0000 & 0.5017 & 0.6332 & 0.5344 & 0.3206 & 0.5669 & 0.3404 & 0.0818 \\
ZUH & 0.0644 & 0.0525 & 0.0156 & 0.0678 & 0.0749 & 0.0870 & 0.0916 & 0.0629 & 0.1022 & 0.1322 \\
TSN & 0.4749 & 0.3731 & 0.0441 & 0.2950 & 0.6239 & 0.5241 & 0.5249 & 0.1418 & 1.0000 & 0.4939 \\
FOC & 0.1044 & 0.1471 & 0.0716 & 0.1619 & 0.2052 & 0.3109 & 0.1783 & 0.0394 & 0.0909 & 0.3244 \\
XMN & 0.0707 & 0.1033 & 0.0561 & 0.1162 & 0.1345 & 0.1191 & 0.1660 & 0.0929 & 0.1185 & 0.1684 \\
\hline
\end{tabular}

Table 5 GRC matrix

\begin{tabular}{lcccccccccc}
\hline & $I_{1}$ & $I_{2}$ & $I_{3}$ & $I_{4}$ & $I_{5}$ & $I_{6}$ & $I_{7}$ & $I_{8}$ & $I_{9}$ & $I_{10}$ \\
\hline SHA & 1.0000 & 1.0000 & 0.9344 & 1.0000 & 1.0000 & 1.0000 & 1.0000 & 1.0000 & 0.9795 & 0.5189 \\
CAN & 0.3463 & 0.3544 & 0.3427 & 0.3577 & 0.3625 & 0.3585 & 0.3711 & 0.3518 & 0.3583 & 0.3718 \\
SZX & 0.3547 & 0.3659 & 0.3465 & 0.3700 & 0.3825 & 0.4167 & 0.3746 & 0.3388 & 0.3512 & 0.4215 \\
ZUH & 0.4838 & 0.4398 & 0.3399 & 0.4111 & 0.5669 & 0.5084 & 0.5088 & 0.3645 & 1.0000 & 0.4931 \\
TSN & 0.4459 & 0.4860 & 0.3631 & 0.5184 & 0.6027 & 0.7288 & 0.7696 & 0.3661 & 0.4145 & 1.0000 \\
FOC & 0.4803 & 0.4938 & 1.0000 & 0.4969 & 0.5730 & 0.5139 & 0.4201 & 0.5319 & 0.4273 & 0.3490 \\
XMN & 0.3447 & 0.3419 & 0.3333 & 0.3456 & 0.3473 & 0.3503 & 0.3514 & 0.3444 & 0.3541 & 0.3619 \\
\hline
\end{tabular}

Table 6 Entropy weight

\begin{tabular}{ccccccccccc}
\hline & $I_{1}$ & $I_{2}$ & $I_{3}$ & $I_{4}$ & $I_{5}$ & $I_{6}$ & $I_{7}$ & $I_{8}$ & $I_{9}$ & $I_{10}$ \\
\hline Weight & 0.0957 & 0.0861 & 0.2031 & 0.0823 & 0.0680 & 0.0637 & 0.0746 & 0.1486 & 0.1028 & 0.0750 \\
\hline
\end{tabular}

Considering the financial performance, the weights for "number of financial sector employees $\left(I_{1}\right)$ ", "financial institutions deposit and loan balance $\left(I_{2}\right)$ ", "total stock turnover $\left(I_{3}\right)$ ", and "total premium income $\left(I_{4}\right)$ " are 0.0957, 0.0861, 0.2031, and 0.0823, respectively, where the weight of "total stock turnover" is the largest among the 10 indicators. This result indicates that "total stock turnover" is the most significant factor related to possibly becoming an IFC. The weights of "GDP $\left(I_{5}\right)$ ", "total retail sales of consumer goods $\left(I_{6}\right)$ ", and "freight traffic $\left(I_{7}\right)$ " in terms of the economic foundations are $0.0680,0.0637$, and 0.0746 , respectively. The weight for "freight traffic" is the smallest among the 10 indicators, which shows that "freight traffic" is relatively less important than the other indicators. In terms of development potential, the weights of "total value of imports and exports $\left(I_{8}\right)$ ", "FDI $\left(I_{9}\right)$ ", and "number of enrolments in colleges and universities $\left(I_{10}\right)$ " are $0.1486,0.1028$, and 0.0750 , respectively.

If the weight of an indicator is higher, the diversification is greater ${ }^{[31]}$. Thus, the indicators with higher weights are relatively more useful than others with lower weights.

\subsection{GRG Calculation}

Next, the entropy weights and the GRCs were combined in GRA to rank the seven cities using Equation (7), where the GRG and the ranking of each city are displayed in Table 7. 
Table 7 GRG matrix

\begin{tabular}{cccccccc}
\hline Indicator & SHA & CAN & SZX & ZUH & TSN & FOC & XMN \\
\hline$I_{1}$ & 0.0957 & 0.0427 & 0.0460 & 0.0330 & 0.0463 & 0.0339 & 0.0331 \\
$I_{2}$ & 0.0861 & 0.0419 & 0.0425 & 0.0295 & 0.0379 & 0.0315 & 0.0305 \\
$I_{3}$ & 0.1898 & 0.0738 & 0.2031 & 0.0677 & 0.0690 & 0.0704 & 0.0696 \\
$I_{4}$ & 0.0823 & 0.0427 & 0.0409 & 0.0284 & 0.0338 & 0.0304 & 0.0294 \\
$I_{5}$ & 0.0680 & 0.0410 & 0.0390 & 0.0236 & 0.0385 & 0.0260 & 0.0246 \\
$I_{6}$ & 0.0637 & 0.0464 & 0.0327 & 0.0223 & 0.0324 & 0.0265 & 0.0228 \\
$I_{7}$ & 0.0746 & 0.0574 & 0.0314 & 0.0262 & 0.0380 & 0.0280 & 0.0277 \\
$I_{8}$ & 0.1486 & 0.0544 & 0.0791 & 0.0512 & 0.0542 & 0.0504 & 0.0523 \\
$I_{9}$ & 0.1007 & 0.0426 & 0.0439 & 0.0364 & 0.1028 & 0.0361 & 0.0368 \\
$I_{10}$ & 0.0389 & 0.0750 & 0.0262 & 0.0271 & 0.0370 & 0.0316 & 0.0279 \\
GRG & 0.9485 & 0.5178 & 0.5847 & 0.3455 & 0.4899 & 0.3649 & 0.3549 \\
Ranking & 1 & 3 & 2 & 7 & 4 & 5 & 6 \\
\hline
\end{tabular}

According to Table 7, Shanghai (SHA) with a value of 0.9485 has the best performance compared with the other cities, followed by Shenzhen (SZX) with a value of 0.5847 , Guangzhou (CAN) with a value of 0.5178 , Tianjin (TSN) with a value of 0.4899 , Fuzhou (FOC) with a value of 0.3649 , Xiamen $(\mathrm{XMN})$ with a value of 0.3549 , and Zhuhai $(\mathrm{ZUH})$ with a value of 0.3455 . These results are basically consistent with the current status of each city.

\section{Discussion and Conclusions}

In this study, we used GRA with entropy to predict the next IFCs in China under the FTZ framework. Tables 6 and 7 show the following: 1) "total stock turnover", "total value of imports and exports", and "FDI" are key indicators of IFCs; 2) among the seven cities considered, Shanghai, Shenzhen, and Tianjin are highly likely to become the next IFCs.

According to the conclusions given above, the government of the IFC should pay greater attention to the indicators with greater weights, especially the "total stock turnover", "total value of imports and exports", and "FDI". If the total stock turnover is higher, the local financial market exhibits higher activity. An active financial market can enhance the liquidity of capital and promote the redistribution of capital. Thus, we can infer that the determination of IFCs depends on the total stock turnover. The total value of the imports and exports and the FDI represent the openness of an IFC. One of the original aims of establishing FTZs is to facilitate financial reform and development by opening up further, which may explain the relative importance of these two indicators.

Furthermore, from the perspective of individual cities, Shanghai is ranked first according to seven of the 10 indicators, excluding "total stock turnover", "FDI", and "number of enrolments in colleges and universities". Shanghai is the financial center of China and it is already an IFC, but the government should expand the influence of Shanghai in Asia further, even into the global financial sector. After Shanghai, Shenzhen exhibits outstanding performance in terms of "financial institutions deposit and loan balance", "total stock turnover", "total value of im- 
ports and exports", and "FDI". Moreover, it should be noted that the "total stock turnover" of Shenzhen has exceeded Shanghai since 2012, which may explain why the "total stock turnover" of Shenzhen is the best among the seven cities and even better than that of Shanghai. Due to their lower economic volumes, it is quite difficult to compare the remaining cities, i.e., Fuzhou, Xiamen and Zhuhai, with the others. Thus, these cities should focus on their specific advantages to generate a differentiated financial center. For example, due to its unique geographical advantage, Xiamen should strengthen its cooperation with the financial sector in Taiwan to build a cross-strait regional financial center.

Finally, Levine ${ }^{[32]}$ suggested that financial development enhances economic efficiency and ultimately growth, by helping to allocate capital toward its best uses. Thus, the development of the financial industry will lead to economic growth, which will consequently increase the demand for financial services to promote the expansion of the financial industry. Based on the coordinated development of finance and the economy, all four FTZs can ease financial restrictions and facilitate financial reform, which are the stated developmental targets of FTZ planning. Therefore, constructing IFCs under the FTZ framework can drive financial reform and innovation, as well as enhancing international trade and foreign investment.

As mentioned above, there is a bidirectional relationship between IFCs and FTZs, which should attract increasing attention and there have been some useful studies of this relationship. However, previous studies focused mainly on evaluating the performance of IFCs, such as London and New York. In addition, a few previous studies employed GRA to determine IFCs, but they assigned equal weights to all of the indicators. The main findings of the present study are as follows: 1) Obtaining weights for all of the indicators based on entropy can distinguish the importance of each indicator; and 2) we proposed a new approach that combines GRA with entropy to determine seven IFCs.

Moreover, this study had some limitations, which require improvements. First, our findings are applicable to seven FTZ cities (potential IFCs), but it is not inappropriate to apply them to other cities. Thus, in future research, more cities may be included. Second, only 10 indicators were selected for the evaluation in this study, but other types of indicators could also be considered.

\section{References}

[1] Bao L L. Free Trade Zone's chemical effect on Shanghai international financial center. Pudong Development, 2014(3): 36-37.

[2] Poon J P H. Hierarchical tendencies of capital markets among international financial centers. Growth and Change, 2003, 34(2): 135-156.

[3] Chen J. Using FTZ's opportunity to promote Shanghai international financial center construction. China Financialyst, 2014(10): 130-131.

[4] Pei C H, Fu C X. The establishment of international financial center and the financial reform of Free Trade Zone in Shanghai. International Economics and Trade Research, 2014, 30(11): 4-18, 65.

[5] Zhu G J. Research on the construction of financial center in Northeast region: From the perspective of financial geography. China university of Geosciences, 2013.

[6] Bu H, Liang X Z, Pi L. A spatial statistic analysis on finance agglomeration and reginal financial development disparities in China. Systems Engineering — Theory \& Practice, 2014, 34(5): 1171-1180.

[7] Liu Y C, Strange R. An empirical ranking of international financial centers in the Asia-Pacific region. The International Executive, 1997, 39(5): 651-674. 
[8] Lu H J. Appraisal on the comprehensive competitiveness of international financial centers. Journal of Finance and Economics, 2007, 33(3): 47-56.

[9] Liu Y. An empirical study on international financial center indicator system construction. Economic Research Guide, 2010(26): 117-118, 158.

[10] Su S J. A study on constructing an evaluation index system of international financial center using Delphi. Science and Technology Management Research, 2010, 30(12): 60-62.

[11] Liang X Z, Yang F M, Bu H, et al. Study on the multilayer financial center system in China based on evaluation of urban financial competitiveness. Systems Engineering - Theory \& Practice, 2011, 31(10): $1847-1857$.

[12] Deng J L. Control problems of grey systems. Systems and Control Letters, 1982, 1(5): 288-294.

[13] Li D C, Chen W C, Chen C C. An extended grey forecasting model for omnidirectional forecasting considering data gap difference. Applied Mathematical Modelling, 2011, 35(10): 5051-5058.

[14] Deng J L. Introduction to grey system theory. Journal of Grey System, 1989, 1(1): 1-24.

[15] Hu Y C. Toleranceroughsetsforpatternclassification usingmultiplegrey single-layerperceptrons. Neruocomputing, 2016, 179(29): 144-151.

[16] Hu Y C, Chiu Y J, Liao Y L, et al. A fuzzy similarity measure for collaborative filtering using nonadditive grey relational analysis. Journal of Grey System, 2015, 27(2): 93-103.

[17] Hsu P F, Kuo M H. An application of the GRA \& Entropy to select a city in China for an international business office center. Journal of Grey System, 2007, 19(3): 269-282.

[18] Shannon C E. A mathematical theory of communication. The Bell System Technical Journal, 1948, 27: 379-423.

[19] Iacono J. Expected asymptotically optimal planar point location. Computational Geometry, 2004, 29(1): 19-22.

[20] Zou Z H, Yun Y, Sun J N. Entropy method for determination of weight of evaluating indicators in fuzzy synthetic evaluation for water quality assessment. Journal of Environmental Sciences, 2006, 18(5): 10201023.

[21] Lin S J, Lu I J, Lewis C. Grey relation performance correlations among economics, energy use and carbon dioxide emission in Taiwan. Energy Policy, 2007, 35(3): 1948-1955.

[22] Chan J W K, Tong T K L. Multi-criteria material selections and end-of-life product strategy: Grey relational analysis approach. Materials \& Design, 2007, 28(5): 1539-1546.

[23] Kung C Y, Wen K L. Applying grey relational analysis and grey decision-making to evaluate the relationship between company attributes and its financial performance - A case study of venture capital enterprises in Taiwan. Decision Support Systems, 2007, 39(3): 842-852.

[24] Kuo Y, Yang Y, Huang G W. The use of grey relational analysis in solving multiple attribute decisionmaking problems. Computer and Industrial Engineering, 2008, 55(1): 80-93.

[25] Lin Y H, Lee P C, Chang T P, et al. Multi-attribute group decision making model under the condition of uncertain information. Automation in Construction, 2008, 17(6): 792-797.

[26] Fung C P. Manufacturing process optimization for wear property of fiber-reinforced polybutylene terephthalate composites with grey relational analysis. Wear, 2003, 254(3-4): 298-306.

[27] Huang R. An empirical analysis of international financial center evaluation index system. Financial Theory and Practice, 2007(6): 39-41.

[28] Hu J, Yang S L. The building up of a valuation indicator system of international financial centre. Journal of Peking University (Philosophy and Social Sciences), 2003, 40(5): 40-47.

[29] Hu L Q, Xia F. Evaluation index system of regional international financial center: Compare and evaluate Kunming and surrounding major cities. Journal of Yunnan University of Finance and Economics, 2012(6): 91-97.

[30] Huang L J. Construction of Nanning regional financial center under the CAFTA framework. Minzu University of China, 2013.

[31] Lee T W, Lin C W, Shin S H. A comparative study on financial positions of shipping companies in Taiwan and Korea using entropy and grey relation analysis. Expert Systems with Applications, 2012, 39(5): 56495657.

[32] Levine R. Financial development and economic growth: Views and agenda. Journal of Economic Literature, 1997, 35(2): 688-726. 